\title{
What evidence exists related to soil retention of phosphorus from on-site wastewater treatment systems in boreal and temperate climate zones? A systematic map protocol
}

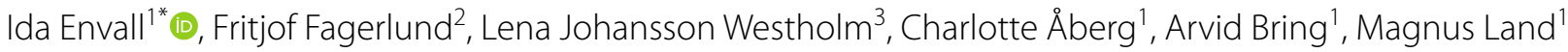
and Jon Petter Gustafsson ${ }^{4,5}$

\begin{abstract}
Background: Soil-based on-site wastewater treatment systems (OWSs) are suspected to contribute to eutrophication of surface waters, due to the discharge of phosphorus (P). However, along the flow path between the facilities and surface waters, different processes contribute to delay the transport of phosphorus through the ground. This may reduce the unwanted impact on receiving water bodies. However, the strength and significance of this so-called soil retention remains unclear.

In Sweden, there are nearly one million OWSs. To protect surface waters, a high P removal rate (up to 90\%) is often required by the local municipalities. However, since these requirements may have costly consequences to property owners, it is debated as to whether they are too strict. In this debate, it is often claimed that the retention of P occurring in natural environments may be underestimated by authorities. Accordingly, there is a need for a scrutiny of the available evidence related to soil retention of phosphorus from OWSs. This is the objective of the planned systematic map. Focus will be on boreal and temperate climate zones.

Methods: Searches will be made for peer-reviewed articles and grey literature using bibliographic databases, search engines, specialist websites and stakeholder contacts. The references will be screened for relevance according to a predefined set of eligibility criteria. At stage one, after testing and clarifying the eligibility criteria, the references will be single-screened based on title and abstract. At stage two, potentially relevant references will be screened in full-text independently by two reviewers. We will compile a detailed database of the relevant studies. Moreover, a narrative report will be produced, describing the research landscape in general terms. This will be carried out with a conceptual model, describing the processes involved in P retention in natural environments, as a foundation. It will be discussed where the respective studies/study types fit into the conceptual model, and also evaluated how each study/study type can be related to the overarching question of eutrophication. Moreover, we will describe identified knowledge gaps that warrant further primary research effort, as well as identified knowledge clusters that could be suitable for systematic reviews.
\end{abstract}

Keywords: OWS, OWTS, Septic systems, Adsorption, Precipitation, Phosphorus removal, Infiltration, Eutrophication, Sweden

\footnotetext{
${ }^{*}$ Correspondence: ida.envall@formas.se

${ }^{1}$ The Swedish Research Council for Environment, Agricultural Sciences

and Spatial Planning (Formas), Box 1206, 11182 Stockholm, Sweden

Full list of author information is available at the end of the article
}

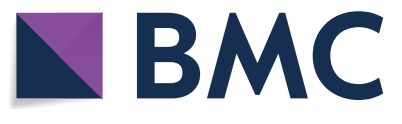

(c) The Author(s) 2020, corrected publication 2020. This article is licensed under a Creative Commons Attribution 4.0 International License, which permits use, sharing, adaptation, distribution and reproduction in any medium or format, as long as you give appropriate credit to the original author(s) and the source, provide a link to the Creative Commons licence, and indicate if changes were made. The images or other third party material in this article are included in the article's Creative Commons licence, unless indicated otherwise in a credit line to the material. If material is not included in the article's Creative Commons licence and your intended use is not permitted by statutory regulation or exceeds the permitted use, you will need to obtain permission directly from the copyright holder. To view a copy of this licence, visit http://creativecommons.org/licenses/by/4.0/. The Creative Commons Public Domain Dedication waiver (http://creativeco mmons.org/publicdomain/zero/1.0/) applies to the data made available in this article, unless otherwise stated in a credit line to the data. 


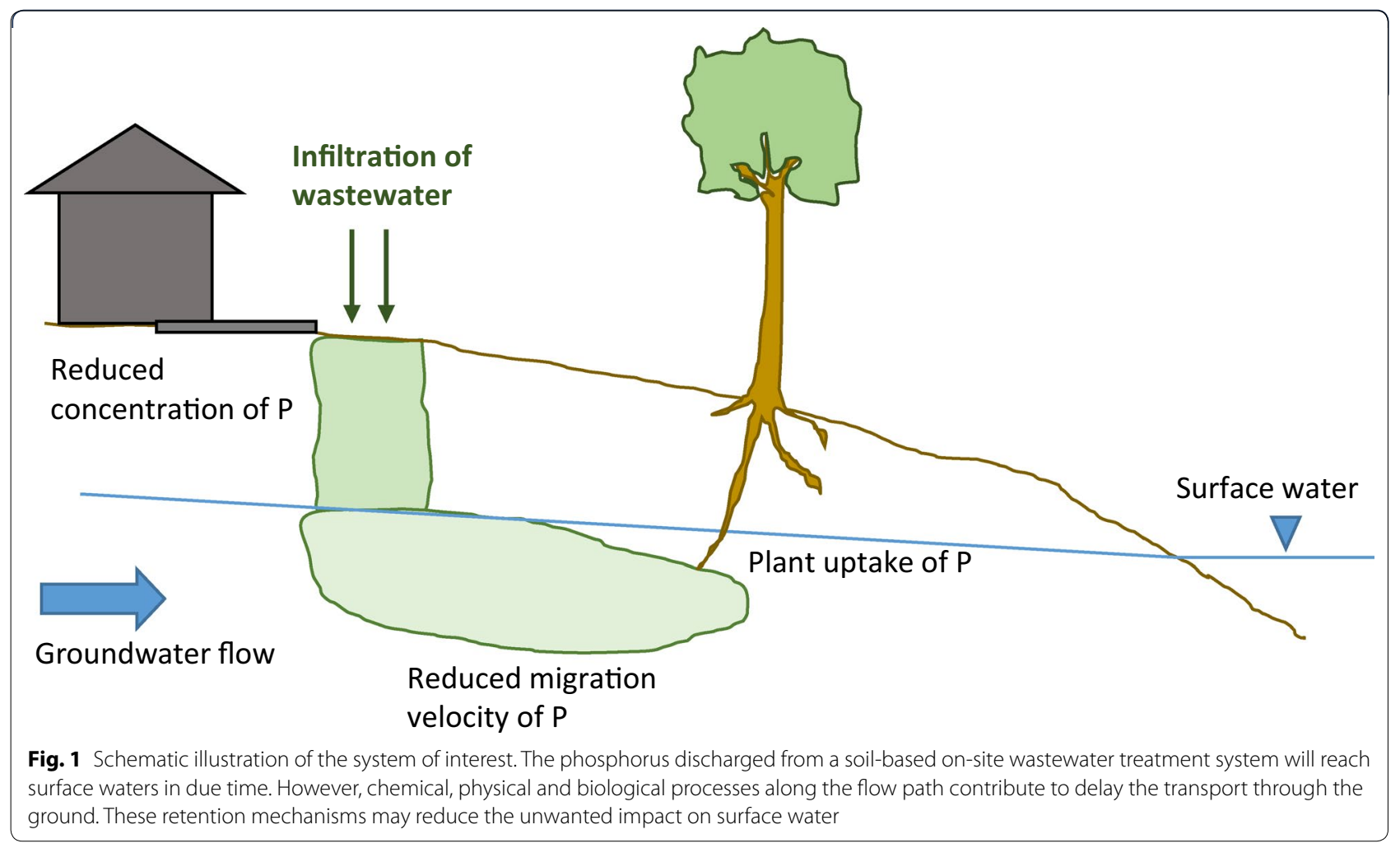

\section{Background}

\section{On-site wastewater treatment systems}

On-site wastewater treatment systems (OWSs) are facilities used for the disposal of wastewater from households that do not have access to a public (municipal) wastewater treatment plant. OWSs are common throughout the world, primarily in rural areas. At least $26 \%$ of the population in most countries is served by an OWS [1].

Typically, an OWS consists of a septic tank in which sludge and pathogens are removed, and a subsequent soil treatment system, where the wastewater is further purified from e.g. phosphorus, nitrogen and pathogens. ${ }^{1}$ There are two main types of soil-based OWSs: the most common discharges to groundwater, whereas the second one (often referred to as 'sand filters') discharges directly to surface waters [2] (although, typically, there is leakage to ground water also from this kind of facility, since the bottom is permeable). The total $\mathrm{P}$ concentration in household wastewater (toilet wastewater and greywater ${ }^{2}$ combined) entering a soil treatment system is usually quite high [3, 4], in Sweden often between 5

\footnotetext{
${ }^{1}$ There are OWSs without a soil infiltration step, for example so called package treatment plants. Such systems are not of interest within this forthcoming systematic map.

${ }^{2}$ Wastewater generated in households, excluding wastewater from toilets.
}

and $15 \mathrm{mg} \mathrm{P} \mathrm{L}^{-1}$ [5], but this $\mathrm{P}$ can to varying degrees be retained by the soil material within the system and between the system and receiving surface water.

\section{A possible connection between on-site wastewater treatment systems and eutrophication.}

The release of phosphorus $(\mathrm{P})$ to surface waters is a global environmental concern, due to the risk of eutrophication. Source appointment models show that municipal wastewater treatment plants and agricultural fields are the most important anthropogenic sources of $\mathrm{P}$ to European surface waters [6], but there are others as well. For example, OWSs are suspected to contribute to the problem. In the Baltic proper, it has been estimated that $15 \%$ of the total Swedish anthropogenic P discharge may be of such origin [7]. However, the estimates are inherently uncertain, partly due to the unclear extent of the retention of $P$ caused by different processes occurring in the ground along the flow path between the facilities and adjacent surface water bodies [2] (Fig. 1).

\section{The Swedish context-the initial motive of the project}

In Sweden, there are nearly one million OWSs [8]. The authorization and control of those are managed through the environmental and health authorities at the local municipalities. However, the Swedish Agency for Marine and Water Management (SwAM) is responsible 


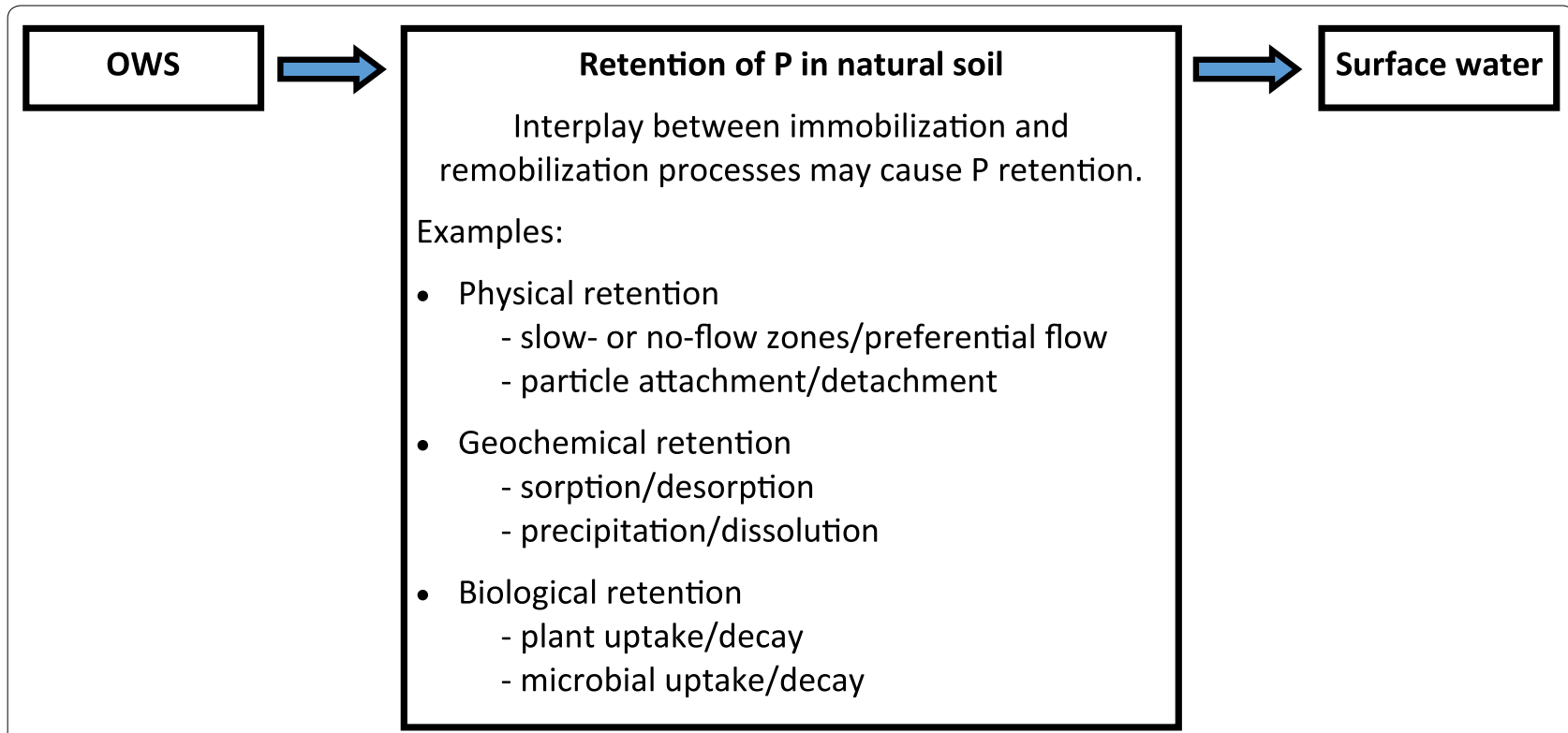

Fig. 2 Flow diagram describing the processes involved in P retention

for the supervisory guidance, providing general recommendations related to OWSs [5]. SwAM recommends up to $90 \%$ P removal under certain conditions. Hence, municipal authorities often require this high level of $\mathrm{P}$ removal, which may have financially severe consequences to households whose facilities do not meet the standards and must be upgraded. Accordingly, there is an ongoing societal debate, e.g. in op-ed articles in the daily Swedish press, as to whether the recommendations and requirements are too strict. In this debate, it is often claimed that the $\mathrm{P}$ retention occurring in the natural soil environment may be considerable, and possibly underestimated by the authorities. For this reason, the Swedish Agency for Marine and Water Management has expressed a need for a scrutiny of all available evidence that is relevant to the question of soil retention (in the natural environment) of $\mathrm{P}$ from onsite wastewater treatment systems. SwAM defines an on-site wastewater treatment system as a wastewater facility designed to serve up to 200 person equivalents. Hence, the evidence included within the forthcoming systematic map should be valid for facilities of this size.

\section{The complexity of soil retention}

The mechanisms of soil retention of $\mathrm{P}$ in the natural environment are complex (Fig. 2) and not fully explored. However, adsorption reactions, which means that $\mathrm{P}$ adheres to soil particles through surface complex formation [9-11], are thought to be dominating. Another mechanism is mineral precipitation, which means that inorganic $\mathrm{P}$ reacts with dissolved iron, aluminium, manganese or calcium to form phosphate minerals [12, 13]. In principle, both these $P$ binding reactions are reversible. That is, $\mathrm{P}$ that has been adsorbed to soil particles may later be desorbed, and phosphate minerals may dissolve. In addition to these physical/chemical reactions, P may be taken up from the wastewater by plants or by microorganisms $[14,15]$. However, any $\mathrm{P}$ assimilated by plants or microorganisms as organic $\mathrm{P}$ will be subject to organic matter decomposition and subsequent mineralization, unless the biomass is harvested and brought away. One process that may counteract the effects of soil retention should be mentioned in this context, namely colloidmediated transport of $\mathrm{P}$, by which the leaching of $\mathrm{P}$ from soils may be accelerated under certain conditions $[16$, 17].

It is often claimed that $\mathrm{P}$ is "removed" by the retention mechanisms described above (adsorption, precipitation and biological uptake). This is, however-partly because of the reversibility of the processes-not necessarily the case. Adsorption and precipitation processes delay, rather than inhibit, the transport of $\mathrm{P}$ through the soil, although slow diffusion into or from small pores can make the response times rather slow [18]. Nevertheless, although most of the $P$ will reach surface waters in due time, the efficiency of soils to retain $\mathrm{P}$ is of crucial importance for the time scale of eutrophication: the more efficient the soil retention is, the less $\mathrm{P}$ will reach the surface water per unit of time, and the less will its possible impact on surface water be. The time scale of the transport and retention is hence important for the practical impact of $P$ released from OWSs. The systematic mapping will not 
be limited to a given time scale, but will strive to map the current knowledge on how time affects the retention under different conditions or circumstances.

\section{A challenging research field}

The overall $\mathrm{P}$ retention efficiency of soils is difficult to estimate, for several reasons. Firstly, the possibility of $\mathrm{P}$ entering into the system from other sources, as well as the possibility of dilution of the wastewater by other water sources, make field measurements challenging. Secondly, each system comprising an OWS together with the flow path between the OWS and the receiving surface water (Fig. 1)-or actually each part of the system-is characterised by a unique combination of factors (concerning, e.g., soil type, hydraulic loading rate, duration of load, content of oxalate-extractable $\mathrm{Fe}$ and $\mathrm{Al}$ ) that may all affect the $\mathrm{P}$ retention. Making things even more complicated, these factors may change over time. For example, eventually, after a prolonged, constant P load, the soil may be "saturated" as regards $\mathrm{P}$, which means that there is no net retention of $\mathrm{P}$ in the soil system anymore. Accordingly, most field studies focus on a specific part of a specific system and are performed at a specific point in time under specific conditions that differ from those that prevailed previously and from those that will prevail later. Generalisations are hence problematic.

A common approach to study soil $\mathrm{P}$ retention is to perform experiments in the laboratory, by letting wastewater infiltrate through soil columns. Such experiments may contribute with valuable information concerning reaction mechanisms and $\mathrm{P}$ dynamics. The merit of laboratory studies is the possibility to control for different confounding factors. On the other hand, generally, such studies are not able to replicate the complexity encountered under field conditions. For this reason, transfer of knowledge gained by laboratory studies to field conditions need to be done with caution.

\section{Examples of study types}

Four main types of studies of obvious relevance to the question may be discerned. Those are described and exemplified below to elucidate the heterogeneity of the research field. However, we will not confine the systematic map to these study types, as is declared under the section Eligibility criteria.

One way to study the efficiency of soils to retain $\mathrm{P}$ is to determine the extent of $P$ retention in the subsurface soil in OWSs [19-24]. Many such studies were conducted already in the 1970s and 1980s. However, the results were often contradictory, some showing efficient and some rather poor P retention. Differences in, e.g., study methods, soil types, and P loads may all be important in explaining the divergent results. When resampling soil treatment systems that had been used for a long time, Eveborn et al. [11, 25] found that in all but one less than $30 \%$ (and sometimes less than 10\%) of the applied P was retained in the top $1 \mathrm{~m}$ of the soil. The exception was the system with the lowest historical P load where almost all of the applied $\mathrm{P}$ was retained. This site, however, was more representative of "typical" Swedish OWSs, as the other sites had been subject to historically very high $\mathrm{P}$ loads. There are other studies showing good long-term $\mathrm{P}$ retention by OWSs [e.g., 26, 27].

In case $\mathrm{P}$ reaches the groundwater zone beneath the OWS, a so-called P plume may be formed, i.e., a volume of groundwater with elevated concentrations of P. The $P$ plume expands mainly in the same direction as the groundwater flow. However, because of the mechanisms occurring in the soil in the saturated zone, the expansion velocity may be retarded as compared to the velocity of surrounding groundwater. In the 1990s and 2000s, Robertson and colleagues studied groundwater P plumes from OWSs, showing that although $\mathrm{P}$ was retained by the soil, at many sites the P migration was still sufficiently fast to cause possible contamination problems if located close to sensitive surface water bodies $[10,28$, 29]. These conclusions have also been supported by studies in which transport models were used to predict the extent of subsurface P migration. Although the results differed in terms of the simulated P migration velocities, they showed that $\mathrm{P}$ does migrate although rather slowly $[4,30]$.

Further, the retention efficiency of soils may be evaluated indirectly by investigating the potential impact of OWSs on surface waters nearby, with regard to the concentration of dissolved P. If there is a clear impact, the retention efficiency of soils may be regarded as "not sufficient", at least not under the specific circumstances under study. Recent research from the UK shows that OWSs may contribute significantly to dissolved P in streams [31, 32]. For example, in the Belton Bridge stream and in a stream near Loddington village, the total $P$ approximately doubled as a result of OWS discharge at two different sampling occasions [32]. These effects were attributed to the high density of OWSs in the studied areas. By contrast, in another British study there was no clear effect on surface water $\mathrm{P}$ concentrations from OWSs, despite poor $P$ retention in the surface layer of the soil $(0-40 \mathrm{~cm})$ [33].

In addition, as mentioned above, soil retention may be studied in the laboratory, by letting wastewater infiltrate through soil columns. Although the transferability of the acquired knowledge from such experiments to natural environments is sometimes questionable, this study type is a straightforward way to study soil retention under controlled conditions. 


\section{Stakeholder involvement}

The systematic map is commissioned by the Swedish Agency for Marine and Water Management, but there are other stakeholders as well. Hence, the Swedish research council Formas arranged a stakeholder meeting where representatives from the Swedish Agency for Marine and Water Management, municipalities, county administrative boards, research institutes, associations representing the interests of property owners, and consultancies within the wastewater treatment domain were invited to discuss potential sources of evidence, study inclusion criteria and potential effect modifiers. During the subsequent development of this protocol, it has become obvious that the complexity of the phenomenon and heterogeneity of the research field calls for a systematic map rather than a systematic review, at least to begin with. At this stage, it has been found challenging to determine an outcome measure that is possible to synthesise and that also is truly useful to stakeholders. This decision has been approved by the Swedish Agency for Marine and Water Management.

An earlier version of this systematic map protocol was sent to all stakeholders who participated at the stakeholder meeting, inviting them to comment on the manuscript. All stakeholders who participated at the stakeholder meeting will also be invited to comment on the forthcoming systematic map manuscript.

\section{Objective of the review}

We will collate, code and configure the relevant evidence related to retention of phosphorus from on-site wastewater treatment systems in natural, not highly weathered soils in boreal and temperate climate zones. The systematic map is commissioned by the Swedish Agency for Marine and Water Management; hence the evidence should be valid for a Swedish context. This is why the mapped evidence base will be confined to the defined soils and climate zones. Accordingly, it will be valid not only for Sweden, but for all parts of the world with boreal and temperate climate. The primary question for the systematic map is: What evidence exists related to retention of $\mathrm{P}$ from on-site wastewater treatment systems in natural, not highly weathered soils in boreal and temperate climate zones? We define soil retention as all retention processes occurring in the (natural) soil environment (for example, also plant uptake is comprised).

The question has the following components:

Subject: Phosphorus in primary or secondary treated domestic wastewater.

Intervention: Infiltration and flow of wastewater through natural (i.e., non-amended as regards $\mathrm{P}$ affinity), not highly weathered soils in boreal and temperate climate zones.
Comparator: Depending on outcome.

Outcome: Any outcome that somehow evaluates the efficiency of soil retention of $\mathrm{P}$.

The systematic map will contain:

1. A detailed database of studies of relevance to the question.

2. A narrative report describing (1) the research landscape in general terms, i.e., what has been studied and how, (2) where the respective studies/study types fit into a conceptual model describing the processes of $\mathrm{P}$ retention, and how each study/study type can be related to the overarching question of eutrophication, (3) implications for policy and practice.

3. A list of knowledge gaps that might warrant further primary research effort, if any such knowledge gap is found.

4. A declaration of identified knowledge clusters that might be suitable for systematic reviews, if any such knowledge cluster is found.

\section{Methods}

The systematic map will follow the Environmental Evidence Guidelines and conforms to the ROSES standards (see Additional file 1).

\section{Searching for articles}

Searches will be made for peer-reviewed articles and grey literature using bibliographic databases, search engines, specialist websites and stakeholder contacts. The reference management software EndNote will be used to collect all search results and to remove duplicates.

\section{Bibliographic database search}

Searches will be made in the 8 bibliographic databases and platforms listed in Table 1. The search strings used will be adapted to the specific syntax in each database. Since this systematic map will include field studies as well as laboratory soil-column studies (for motivation, see under Eligibility criteria) we have developed two different search strings. The two search strings, adapted to the bibliographic database Scopus, can be found in an additional file (see Additional file 2). We will use English search terms in all databases and Swedish search terms in two of the databases that contain publications from Swedish universities and authorities. English search terms usually identify articles in other languages than English, since non-English articles often have a title and abstract in English, and will therefore be retrieved by the searches. We will limit the search to include articles in English, Swedish, Norwegian and Danish. The searches will not be limited by publication date or document type. 
Table 1 Bibliographic databases to be searched

\begin{tabular}{|c|c|c|c|}
\hline Database/platform & Search field & Language of search terms & Subscription information \\
\hline Scopus & Title, Abstract, Keywords & English & $\begin{array}{l}\text { Swedish Research Council Formas } \\
\text { subscription }\end{array}$ \\
\hline Web of Science Core Collection & $\begin{array}{l}\text { Topic (search the fields: title, abstract } \\
\text { and keywords) }\end{array}$ & English & $\begin{array}{l}\text { Swedish Research Council Formas } \\
\text { subscription includes: Science Cita- } \\
\text { tion Index Expanded; Social Sciences } \\
\text { Citation Index; Arts \& Humanities Cita- } \\
\text { tion Index; Conference Proceedings } \\
\text { Citation Index- Science; Conference } \\
\text { Proceedings Citation Index- Social Sci- } \\
\text { ence \& Humanities; Emerging Sources } \\
\text { Citation Index }\end{array}$ \\
\hline Academic Search Premier & $\begin{array}{l}\text { Title, Abstract, Subject Terms, Author- } \\
\text { Supplied Keywords }\end{array}$ & English & $\begin{array}{l}\text { Swedish Research Council Formas } \\
\text { subscription on Ebsco platform }\end{array}$ \\
\hline CAB Abstracts & Title, Abstract, Heading Words & English & $\begin{array}{l}\text { Swedish Research Council Formas } \\
\text { subscription on Ovid platform }\end{array}$ \\
\hline Directory of Open Access Journals ${ }^{a}$ & All fields & English & Free. Do not require a subscription \\
\hline $\operatorname{DiVA}^{a}$ & All fields & English and Swedish & Free. Do not require a subscription \\
\hline ProQuest Natural Science Collection & Title, Abstract, All subjects \& indexing & English & $\begin{array}{l}\text { Swedish Research Council Formas sub- } \\
\text { scription includes: AGRICOLA; Agri- } \\
\text { cultural Science database; Aquatic } \\
\text { Sciences and Fisheries Abstracts; } \\
\text { Biological Science database; Biologi- } \\
\text { cal Science index; Earth, atmosphere } \\
\text { \& Aquatic Science database; Environ- } \\
\text { mental Science database; Environ- } \\
\text { mental Science index; Meteorological } \\
\text { \& Geoastrophysical Abstracts }\end{array}$ \\
\hline SwePuba & All fields & English and Swedish & Free. Do not require a subscription \\
\hline
\end{tabular}

a A simplified search string will be used and published in the final report

\section{Estimating the comprehensiveness of the search}

A list of benchmark studies (see Additional file 3) was used during the development of the search strings and to test the comprehensiveness of the search. The bibliographic database Scopus was used when developing the search strings and testing whether the benchmark studies were found. If any of the benchmark studies had been missed, the search strings were adapted to include the missed studies. The list of search terms identified were evaluated by experts and new search terms were added after consulting with experts and stakeholders.

\section{Search engines}

Literature will also be searched for using the search engine Google Scholar, using simplified search strings in English and Swedish. Those search strings are presented in Additional file 2. The first 200 results for every search will be exported from Google Scholar using Publish or Perish software [34].

\section{Websites of relevant organisations}

Websites of the organisations in Table 2 will also be searched, using the same search strings as for Google
Scholar when applicable, in Swedish or English, depending on the appropriate language for the website. All search strings and matching results will be published in the final report.

\section{Supplementary searches}

We will contact stakeholders and experts in the field to request studies and reports. We will screen the bibliographies of other reviews, identified during the article screening process, in order to identify additional applicable studies.

\section{Article screening and study eligibility criteria Screening process}

After removal of duplicates, the references will be screened for relevance based on title and abstract. To ensure the consistency of decisions regarding inclusion and exclusion between reviewers, articles will be screened by multiple authors of this protocol independently. Disagreements will be analysed and the inclusion/exclusion criteria will be revisited and evaluated, and-when found necessary-clearer defined. This process will be repeated until we will be able to ascertain that the reviewers 
Table 2 Organisational websites to be searched

\begin{tabular}{|c|c|}
\hline Organisation & URL \\
\hline \multicolumn{2}{|l|}{ Organisations in Europe } \\
\hline EEA (European Environment Agency) & https://www.eea.europa.eu \\
\hline DCE (Danish Centre for Environment and Energy) & https://dce.au.dk \\
\hline Miljøstyrelsen (Danish Environmental Protection Agency) & https://mst.dk \\
\hline Luke (Natural Resources Institute Finland) & https://www.luke.fi \\
\hline SYKE (Finnish Environment Institute) & https://www.syke.fi \\
\hline Umweltbundesamt (German Environment Agency) & https://www.umweltbundesamt.de \\
\hline $\begin{array}{l}\text { PIA (Development and assessment institute in waste water technology at RWTH Aachen University, } \\
\text { Germany) }\end{array}$ & $\begin{array}{l}\text { https://www.pia-gmbh.com } \\
\text { https://www.pia.rwth-aachen.de }\end{array}$ \\
\hline EPA Ireland (Environmental Protection Agency, Ireland) & https://epa.ie \\
\hline STOWA (Foundation for Applied Water Research, in the Netherlands) & https://www.stowa.nl \\
\hline Wageningen Environmental Research (Research Institute in the Netherlands) & $\begin{array}{l}\text { https://www.wur.nl/en/Research-Results/ } \\
\text { Research-Institutes/Environmental-Resea } \\
\text { rch.htm }\end{array}$ \\
\hline Miljødirektoratet (Norwegian Environment Agency) & https://www.miljodirektoratet.no \\
\hline $\mathrm{NIBIO}$ (Norwegian Institute of Bioeconomy Research) & https://www.nibio.no \\
\hline NIVA (Norwegian Institute for Water Research) & https://www.niva.no \\
\hline NTNU (Norwegian University of Science and Technology) & https://www.ntnu.no \\
\hline Tidsskriftet VANN (Water, a Norwegian journal) & https://vannforeningen.no/tidsskriftet-vann \\
\hline Havs-och vattenmyndigheten (Swedish Agency for Marine and Water Management) & https://www.havochvatten.se \\
\hline IVL (Swedish Environmental Research Institute) & https://www.ivl.se \\
\hline Länsstyrelser i Sverige (County Administrative Boards in Sweden) & https://www.lansstyrelsen.se \\
\hline Naturvårdsverket (Swedish Environmental Protection Agency) & https://www.naturvardsverket.se \\
\hline SGU (Geological Survey of Sweden) & https://www.sgu.se \\
\hline SLU (Swedish University of Agricultural Sciences) & https://www.slu.se \\
\hline SMED (Swedish Environmental Emissions Data) & https://www.smed.se \\
\hline Svenskt Vatten (Swedish Water \& Wastewater Association) & https://www.svensktvatten.se \\
\hline Tidskriften Vatten (Water, a Swedish journal) & https://www.tidskriftenvatten.se \\
\hline DEFRA (Department for Environment, Food \& Rural Affairs) & $\begin{array}{l}\text { https://www.gov.uk/government/organ } \\
\text { isations/department-for-environmen } \\
\text { t-food-rural-affairs }\end{array}$ \\
\hline SEPA (Scottish Environmental Protection Agency) & https://www.sepa.org.uk \\
\hline \multicolumn{2}{|l|}{ Organisations in North America } \\
\hline INRS (The Institut national de la recherche scientifique, in Canada) & https://www.inrs.ca \\
\hline EPA U.S. (Environmental Protection Agency, United States) & https://www.epa.gov \\
\hline NOWRA (National Onsite Wastewater Recycling Association) & https://www.nowra.org/ \\
\hline \multicolumn{2}{|l|}{ Organisations in other parts of the world } \\
\hline CSIRO (Commonwealth Scientific and Industrial Research Organisation, in Australia) & https://www.csiro.au \\
\hline
\end{tabular}

interpret the agreed inclusion and exclusion criteria equally and apply them in a consistent way. In total, 700 articles will be used for consistency checking. Thereafter, titles and abstracts will be single screened, although in an utterly inclusive manner. Reviewers will have three options during screening at this stage: (1) include, (2) exclude, or (3) maybe. All articles coded with option 3 will then be separately screened by another author, after which a consensus decision will be made.

All articles included after this process will be screened for relevance in full-text. The screening process at this level will be performed in couples, independently of each other within each couple. Any disagreement will be discussed by all reviewers.

Reviewers will not be allowed to assess the relevance of articles that they have authored themselves.

\section{Eligibility criteria}

Eligible types of study design Any study design will be accepted; however, there must be a control. Modelling studies will not be included unless there are relevant 
empirical data used to validate models. (For eligible study types, see below.)

Eligible subject The subject is phosphorus within primary or secondary treated domestic wastewater. The evidence of the forthcoming systematic map should be valid for soil-based on-site wastewater treatment systems designed to serve up to 200 person equivalents (in accordance with the definition made by the Swedish Agency for Marine and Water Management). As regards field studies, the wastewater must hence originate from single or groups of households and be released to a soil-based wastewater treatment system. Field studies on wastewater from municipal wastewater treatment plants will not be included. However, as regards laboratory studies, using wastewater from municipal wastewater treatment plants will also be accepted. Studies focusing on, e.g., stormwater, industrial wastewater, wastewater from animal farms, or agricultural wastewater will be excluded, as will studies using synthetic wastewater. Further, studies focusing on $\mathrm{P}$ leaching from sewage sludge will be excluded.

Eligible intervention Infiltration and flow of wastewater through natural (i.e., non-amended as regards $\mathrm{P}$ affinity) soil. The soil must not be highly weathered (e.g., studies on Oxisols, Ultisols and other strongly weathered soils and aquifer materials will not be eligible). Field studies must be performed within climate zones $\mathrm{C}$ or $\mathrm{D}$ according to Köppen-Geiger climate classification system [35]. Field studies of $\mathrm{P}$ retention in wetlands will not be included, since focus of the forthcoming systematic map is on the soil environment. However, laboratory column studies, evaluating natural soil materials from wetlands, may be included. The effect of phosphorus uptake by plants on soil $\mathrm{P}$ retention is included in an indirect fashion in e.g. studies on OWS influence on surface water bodies. However, studies focusing solely on plant uptake of phosphorus will not be included, since such studies do not have the potential to contribute to answer the question of soil retention.

Eligible comparators The studies must include a control. However, the comparator depends on outcome. For example, when it comes to column studies, the P concentration of the wastewater after infiltration must be compared with the $\mathrm{P}$ concentration of the wastewater before infiltration. When it comes to P plume studies, the retardation of the expansion of the P plume must be compared with the velocity of the surrounding groundwater.

Eligible outcomes Any outcome that somehow evaluates (the efficiency of) the retention of $\mathrm{P}$ in the soil, including-but not restricted to-retardation of the expansion of the $\mathrm{P}$ plume compared to the velocity of the groundwater, reduced $\mathrm{P}$ concentration in the water after infiltration, or increased concentration of $\mathrm{P}$ in surface water. Regarding the last example, increased concentration of $\mathrm{P}$ in surface water, the contribution of P from OWSs, specifically, must be evaluated and analysed in the study. If not, the study will be excluded, since no causality may be determined in those cases.

Eligible study types We will include field studies (including surface water monitoring studies) and laboratory studies based on soil column experiments. Although column studies are not able to replicate the complexity encountered under field conditions, we consider them as a valuable part of the evidence base related to soil retention of P. The merit of laboratory studies is the possibility to study how various parameter combinations affect the $\mathrm{P}$ retention capacity in soil, and to have control over the actual in- and outflow of wastewater. Hence, they give important complementary information, useful not the least while interpreting the results from field studies. Batch studies, in which soil samples are shaken with solutions for a certain amount of time, and then centrifuged/ filtered to separate the solution from the solid phase, will not be included. The rationale for including column studies but not batch studies is that column studies attempt to mimic natural flow though soil. In batch studies, however, there is no removal of reaction products and of desorbed $\mathrm{P}$, which complicates the interpretation regarding their relevance for field conditions even more. Hence, the transferability of results is considered to be significantly higher for soil column studies.

Eligible languages English, Swedish, Norwegian and Danish.

A flow diagram, clarifying the criteria guiding the screening process, is presented in Fig. 3.

Given the presumed high number of articles to screen, only articles excluded at full-text level will be coded with a reason for exclusion. A list of excluded articles, with reasons for exclusion, will be provided.

\section{Study validity assessment}

We will not perform a critical validity assessment of each included study, since we do not intend to make syntheses of results. Moreover, our open-framed question makes it impossible to foresee exactly what study types will be found, and hence it is not possible to firmly determine study validity criteria a priori. Nevertheless, as part of our data coding strategy, we will collect information that may help describing the characteristic qualities of the evidence base, which may give a preliminary idea of its rigor. Examples include: correction for dilution by other 


\section{Include}

\section{Exclude}

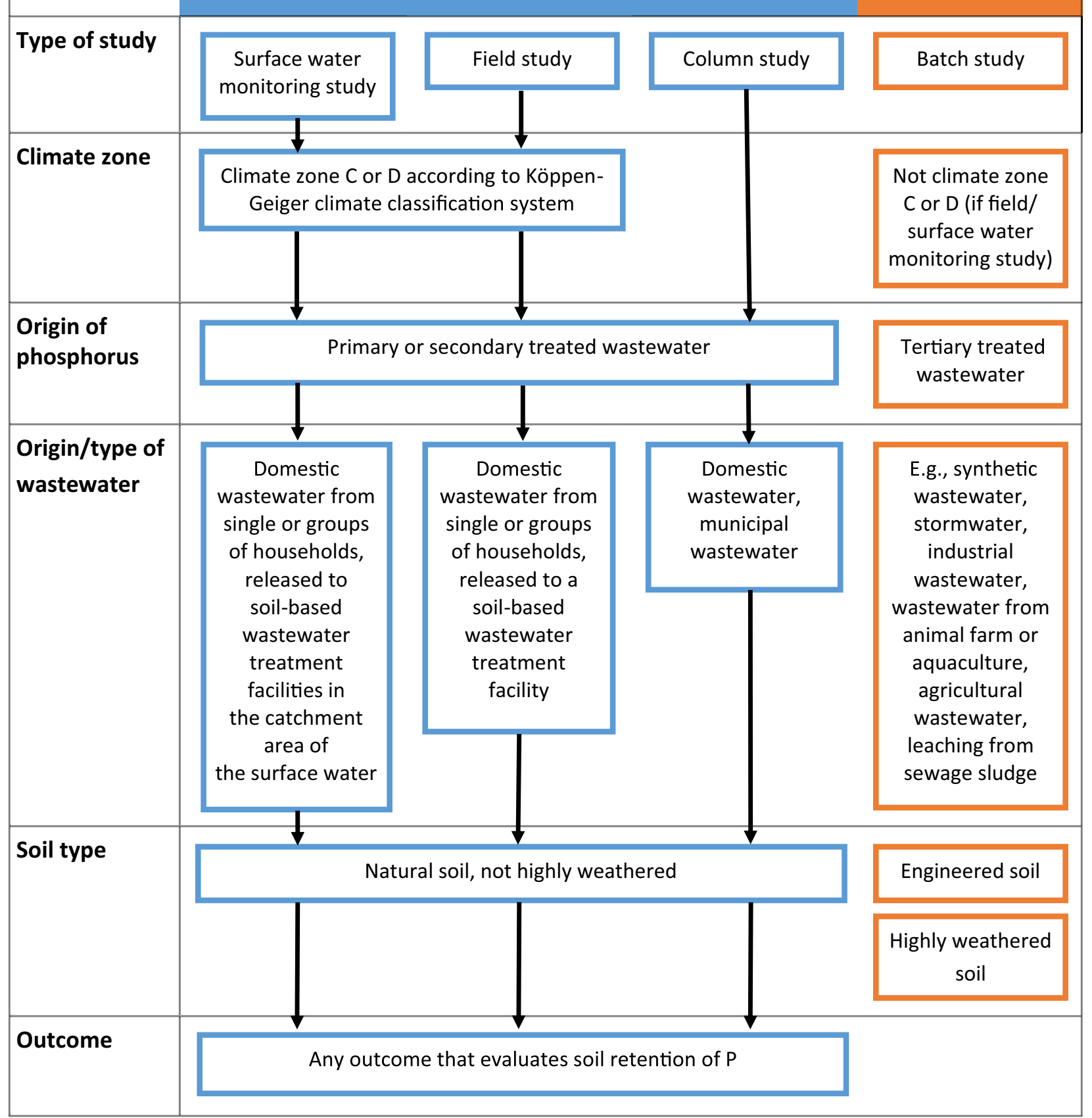

Fig. 3 Flow diagram clarifying the criteria guiding the screening process. The exclusion criteria are given as examples, for the sake of clarity; they are actually logical consequences of the inclusion criteria

water sources, correction for background $\mathrm{P}$, number of replicates, and sampling density within each replicate.

\section{Data coding strategy}

The following data will be coded for each study:
- Bibliographic information (author, year, title, publication type, place published, language)

- Study setting (field study or laboratory study)

- Brief study description

- Study location (country and, if available, coordinates) 
Whenever possible/relevant, the following studydesign related data will be coded:

- Strategy to correct for dilution

- Strategy to correct for background P/leakage from other sources

- Number of replicates and sampling density

- Length of study

- Time of year when the study was performed

- Size of columns

Whenever possible/relevant, the following data related to possible effect modifiers will be coded:

- Soil type

- $\mathrm{pH}$ of soil or of soil water

- Mineralogy

- Grain size distribution

- Bulk density

- Porosity

- Hydraulic conductivity

- Soil water saturation (as regards field studies: saturated or unsaturated zone)

- Hydraulic loading rate

- Duration of wastewater effluent load/age of facility

- Dissolved P concentration in the wastewater

- Type of wastewater (on-site or municipal)

- Composition of wastewater

- Concentration of oxalate-extractable iron

- Concentration of oxalate-extractable aluminum

- Concentration of total and/or sorbed P in the soil

- Type of OWS

- Distance to surface water

- Climate zone

However, given the open-framed question, a certain degree of iterativity is supposed to be necessary. That is, we do not rule out that also other types of data will be coded.

To ensure a repeatable and consistent data coding procedure, two reviewers will code data from a subset of articles (at least 15). In case of inconsistencies, the coding methodology will be discussed, evaluated and refined. Thereafter, the data from each article will be coded by one reviewer. However, any uncertainty will be discussed with the other reviewers. The data will be entered into a pre-designed Excel data sheet.

Given the expected large amount of studies to be included in the systematic map, and given the large amount of different kinds of data suggested to be coded for each study, we will not be able to contact authors if any of these suggested data types is missing or unclear.

\section{Study mapping and presentation}

We will present the results in a systematic map report in the journal Environmental Evidence. Within the report, the systematic mapping process will be represented through a flow diagram, describing the number of studies found through searches, the number of studies included and excluded during respective screening stage, and the number of studies included in the final systematic map.

The evidence base will be described narratively, and summarized with tables and figures, in accordance with CEE guidelines. The final data coding form will be provided, including the study characteristics recorded during data coding.

A conceptual model describing the processes involved in soil retention of $\mathrm{P}$ in natural environments will be used as a foundation for a discussion on what utilitarian knowledge that can be inferred from existing research, about soil retention of $\mathrm{P}$ from on-site wastewater treatment systems. The aim is to guide stakeholders who intend to take research into consideration while developing or evaluating policy and practice related to on-site wastewater treatment facilities.

Knowledge gaps and clusters, respectively, will be identified by visual inspection of heat maps created by cross-tabulating different key descriptors (e.g. study type and outcome). The assessment will be performed by two methodology experts of the review team.

In case we identify any knowledge gaps that warrant further primary research effort, we will present those. In case we identify any knowledge clusters, we will present those as well, and consider and briefly discuss whether they appear to be suitable for systematic reviews. However, final prioritization of primary research questions as well as of systematic review questions needs thorough engagement with stakeholders and is beyond the scope of this systematic map.

\section{Supplementary information}

Supplementary information accompanies this paper at https://doi. org/10.1186/s13750-020-00205-9.

Additional file 1. ROSES form. Our adherence to the ROSES standards for systematic map protocols.

Additional file 2. Search strings. Search strings adapted to Scopus and Google Scholar.

Additional file 3. Benchmark studies. List of benchmark studies used to test the comprehensiveness of the search.

\section{Acknowledgements}

The preparation of this protocol and the forthcoming systematic map is financed by the Swedish Research Council for Environment, Agriculture Sciences and Spatial planning (Formas). The authors wish to thank Dr. Aleksandra Drizo and an anonymous reviewer for constructive comments. We are also grateful for many valuable comments provided by Swedish stakeholders during a public review of an earlier version of this protocol. 


\section{Authors' contributions}

The systematic map protocol is based on a draft written by IE and JPG. C is the main author of the section about literature searching. All authors discussed, edited and added text to the draft. All authors read and approved the final manuscript.

\section{Funding}

Open access funding provided by The Swedish Research Council Formas. The systematic review protocol is funded by Formas. IE, $C \AA, A B$ and $M L$ are employed by Formas.

\section{Availability of data and materials}

Not applicable.

\section{Ethics approval and consent to participate}

Not applicable.

\section{Consent for publication}

Not applicable.

\section{Competing interests}

The authors declare that they have no competing interests.

\section{Author details}

${ }^{1}$ The Swedish Research Council for Environment, Agricultural Sciences and Spatial Planning (Formas), Box 1206, 11182 Stockholm, Sweden. ${ }^{2}$ Department of Earth Sciences, Uppsala University, Villavägen 16, 75236 Uppsala, Sweden. ${ }^{3}$ School of Business, Society and Engineering, Mälardalen University, P.O. Box 883, 72123 Västerås, Sweden. ${ }^{4}$ Department of Soil and Environment, Swedish University of Agricultural Sciences, Box 7014, 75007 Uppsala, Sweden. ${ }^{5}$ Department of Sustainable Development, Environmental Science and Engineering, KTH Royal Institute of Technology, Teknikringen 10B, 100 44 Stockholm, Sweden.

Received: 16 April 2020 Accepted: 7 September 2020

Published online: 14 September 2020

\section{References}

1. Drizo A. Phosphorus pollution control_-policies and strategies. 1st ed. Hoboken: John Wiley \& Sons; 2020.

2. Eveborn D. Sustainable phosphorus removal in onsite wastewater treatment. PhD Thesis, TRITA-LWR PHD 1070. Stockholm: KTH Royal Institute of Technology; 2013.

3. Canter $L, K$ nox RC. Evaluation of septic tank system effluents on ground water quality. Report EPA-600/2-84-107. Ada: US Environmental Protection Agency; 1984.

4. Speed CD, Fretwell BA, Davison PS. The role of septic tanks in the dissolved phosphorus budget of the Upper River Nar and possible implications for other catchments. Q J Eng Geol Hydroge. 2019;52:23-37.

5. Swedish Agency for Marine and Water Management (SwAM). SwAM's general recommendations for small-scale wastewater treatment systems (HVMFS 2016:17). 2016.

6. European Environment Agency. Source appointment of nitrogen and phosphorus inputs to the aquatic environment EEA. Report 7/2005. Copenhagen: European Environment Agency; 2005.

7. Ejhed H, Widén-Nilsson E, Tengdelius Brunell J, Hytteborn J. Näringsbelastningen på Östersjön och Västerhavet 2014. Havs- och Vattenmyndighetens Rapport 2016:12 (in Swedish). Göteborg: Swedish Agency for Marine and Water Management; 2016.

8. Olshammar M. Utsläpp från små avloppsanläggningar 2017. SMED Rapport 6 (in Swedish). Norrköping: Swedish Meteorological and Hydrological Institute (SMHI); 2018.

9. Goldberg S, Sposito G. A chemical model of phosphate adsorption by soils: I. Reference oxide minerals. Soil Sci Soc Am J. 1984;48:772-8.

10. Robertson WD. Irreversible phosphorus sorption in septic system plumes? Ground Water. 2008:46:51-60.

11. Eveborn D, Gustafsson JP, Elmefors E, Yu L, Eriksson AK, Ljung E, Renman G. Phosphorus in soil treatment systems: accumulation and mobility. Water Res. 2014;64:42-52.
12. Zanini L, Robertson WD, Ptacek CJ, Schiff SL, Mayer T. Phosphorus characterization in sediments impacted by septic effluent at four sites in central Canada. J Contam Hydrol. 1998;33:405-29.

13. Zurawsky MA, Robertson WD, Ptacek CJ, Schiff SL. Geochemical stability of phosphorus solids below septic system infiltration beds. J Contam Hydrol. 2004;73:129-43.

14. Liu W, Cui LH, Zhou YP, Lei ZX. Removal of total phosphorus from septic tank effluent by the hybrid constructed wetland system. Proc Environ Sci. 2011;C10:2102-7.

15. Mechtensimer S, Toor GS. Fate, mass balance, and transport of phosphorus in the septic system drainfields. Chemosphere. 2016;159:153-8.

16. Ilg K, Siemens J, Kaupenjohann M. Colloidal and dissolved phosphorus in sandy soils as affected by phosphorus saturation. J Environ Qual. 2005;34:926-35.

17. Liu J, Aronsson H, Bergström L, Sharpley A. Phosphorus leaching from loamy sand and clay loam topsoils after application of pig slurry. Spring erPlus. 2012;1:53.

18. Barrow NJ. On the reversibility pf phosphate sorption by soils. J Soil Sci. 1983;34:751-8

19. Reneau RB, Pettry DE. Phosphorus distribution from septic tank effluent in Coastal Plain soils. J Environ Qual. 1976;5:34-9.

20. Sawhney BL, Starr JL. Movement of phosphorus from a septic system drainfield. JWPCF. 1977;49:2238-42.

21. Jones R, Lee G. Septic tank wastewater disposal systems as phosphorus sources for surface waters. JWPCF. 1979:51:2764-75.

22. Gilliom R, Patmont C. Lake phosphorus loading from septic tank systems by seasonally perched groundwater. JWPCF. 1983;55:1297-305.

23. Nilsson P, Stuanes AO. Investigation of soil treatment systems for septic tank effluent: 1. Design, function, hydraulic properties, input and output. Vatten. 1987:43:26-37.

24. Pell M, Nyberg F. Infiltration of wastewater in a newly started pilot sandfilter system: I. Reduction of organic matter and phosphorus. J Environ Qual. 1989:18:451-7.

25. Eveborn D, Kong D, Gustafsson JP. Wastewater treatment by soil infiltration: long-term phosphorus removal. J Contam Hydrol. 2012:140-141:24-33.

26. Gill LW, O'Luanaigh N, Johnston PM, Misstear BDR, O'Suilleabhain C. Nutient loading on subsoils from on-site wastewater effluent, comparing septic tank and secondary treatment systems. Water Res. 2009:43:2739-49.

27. Robertson WD. Phosphorus retention in a 20-year-old septic system filter bed. J Environ Qual. 2012:41:1437-44.

28. Robertson WD. Development of steady-state phosphate concentrations in septic system plumes. J Contam Hydrol. 1995;19:289-95.

29. Robertson WD, Schiff SL, Ptacek CJ. Review of phosphate mobility and persistence in 10 septic system plumes. Ground Water. 1998;36:1000-10.

30. Spiteri C, Slomp CP, Regnier P, Meile C, van Cappellen P. Modelling the geochemical fate and transport of wastewater-derived phosphorus in contrasting groundwater systems. J Contam Hydrol. 2007;92:87-108.

31. Withers PJA, Jordan P, May L, Jarvie HP, Deal NE. Do septic tank systems pose a hidden threat to water quality? Front Ecol Environ. 2014;12:123-30.

32. May L, Place C, O'Malley M, Spears B. The impact of phosphorus inputs from small discharges on designated freshwater sites. Natural England Commissioned Reports, Number 170;2015.

33. Batista Seguí MdM, Tyrrel S, Hess T, Sakrabani R, Knaggs D. Long-term phosphorus accumulation and removal efficiency in a land-based wastewater treatment system in the UK. Water Environ J. 2019;33(4):589-98.

34. Harzing AW. Publish or Perish. 2007. https://harzing.com/resources/publi sh-or-perish. Accessed 19 Nov 2019.

35. Beck HE, Zimmermann NE, McVicar TR, Vergopolan N, Berg A, Wood EF. Present and future Köppen-Geiger climate classification maps at 1-km resolution. Scientific Data. 2018;5:180214. https://doi.org/10.1038/sdata .2018 .214 .

\section{Publisher's Note}

Springer Nature remains neutral with regard to jurisdictional claims in published maps and institutional affiliations. 